\title{
KNOWLEDGE AND AWARENESS OF FEMALE SEX WORKERS TOWARDS HUMAN PAPILLOMAVIRUS INFECTION IN TURKEY
}

\author{
Gürsel Ersan', Şükran Köse', Habibe Güneş², Mehmet Özkan³ \\ ${ }^{1}$ Department of Infectious Diseases and Clinical Microbiology, Tepecik Research and Training Hospital, Izmir, Turkey \\ ${ }^{2}$ Brothel Physician, Izmir, Turkey \\ ${ }^{3}$ Izmir Branch of the Ministry of Health, Izmir, Turkey
}

\begin{abstract}
SUMMARY
Objective: The aim of this study was to determine the knowledge and awareness of female sex workers (FSWs) about human papillomavirus (HPV) infection in Turkey.

Methods: 239 brothel-based FSWs were recruited for an interview. A questionnaire was completed by face to face interview. The demographic features, the level of knowledge, and awareness about HPV infection of the participants were recorded.

Results: A total of $152(63.6 \%)$ were over 30 years of age, and $210(87.9 \%)$ completed primary education. 122 FSWs (50.9\%) were using condom, and about one third had high frequency of sexual contacts. Knowledge scores were $\leq 4$ in $181(75.7 \%)$ FSWs. Low education and higher age group were not significant predictors of low knowledge scores. Low education was not an independent risk factor for awareness but higher age group participants were significantly less aware of risks associated with HPV infection $(p=0.019)$ although overall score was very poor $(0.60 \pm 0.68)$.

Conclusions: The knowledge and awareness about HPV infection and its possible consequences (cervical cancer) as well as the utility of screening methods among FSWs in Turkey are extremely poor. HPV-focused educational programmes for targeted populations, e.g. FSWs and young adults prior to their sexual activity, should be launched urgently to increase awareness of the risks associated with HPV infection and thus reducing the incidence of cervical cancer in Turkey in the future.
\end{abstract}

Key words: human papilloma virus, sex workers, knowledge

Address for correspondence: Gürsel Ersan, Department of Infectious Diseases and Clinical Microbiology. Tepecik Research and Training Hospital, 35110, Konak, Izmir, Turkey. E-mail: ersangursel@gmail.com

\section{INTRODUCTION}

Cervical cancer, the second most common cancer in women in developing regions, is the 10 th most common cancer in developed regions worldwide (1-3). Approximately 9,000 women develop cervical cancer and about 4,600 die from the disease each year in Southeast Europe (4). It ranks the ninth most common cancer among women in Turkey (5).

Cervical cancer is one of the most preventable cancers. Elucidation of the casual role of oncogenic HPV types in cervical cancer has led to rapid advances in HPV testing and vaccination to improve cervical cancer prevention (4). Genital HPV types have been subdivided into low-risk types, which are found mainly in genital warts, and high-risk types (HR-HPV), which are frequently associated with invasive cervical cancer (1). Based on HPV type-specific odds ratios and HPV prevalence among patients and controls, Munoz et al. identified 15 HPV types as high-risk types $(16,18,31,33,35,39,45,51,52,56,58,59,68$, 73, and 82) (1). Types 16 and 18 are the most dangerous ones and together account for over $70 \%$ of cervical cancer cases (2). The most common types were types $16,45,18$, and 31 among Turkish females living in south-eastern region (6).
Sex workers represent the high risk group for all sexually transmitted diseases and especially HPV infection is significantly more prevalent among FSWs than control groups (7). HR-HPV types are high in FSWs than in women from the general population. Therefore, they comprise the priority group for active surveillance against HPV infection and cervical cancer (7-10).

A quadrivalent vaccine against HPV types 6, 11, 16 and 18 was approved by the United States (US) Food and Drug Administration (FDA) on June, 2006, and a bivalent vaccine against types 16 and 18 was approved by the European Commission in September, $2007(11,12)$. Previous studies demonstrated that the knowledge and awareness about HPV infection and its consequences, and about screening methods for cervical cancer and attitudes toward vaccination were generally low (13-15). Onan et al. from Turkey demonstrated also that women in general population required more information about both HPV infection and vaccine-related issues (16).

An effective preventive programme assumes widespread use of Pap smear and/or HPV DNA testing, use of barrier methods, increasing the public understanding about HPV, implementation of vaccination programmes for a naive population, and for females who are not yet sexually active, because the vaccines have the 
potential to improve cervical cancer control through primary prevention $(13,17)$. Preventive programme should be supported by health promotion activities aimed at better understanding and awareness of the general public about the relation between HPV and cervical cancer (7).

This study was designed to measure the knowledge and awareness of FSWs about HPV infection and its possible consequences in Turkey. This study, the first of its kind in our country, aimed to clarify the necessity for well-designed, HPV-focused educational programmes in Turkey, and in developing countries.

\section{MATERIALS AND METHODS}

\section{Study Population}

Ethical approval was obtained from local Ethical Committee of our centre. A total of 239 FSWs were included in the study. After obtaining informed consent, each participant completed a questionnaire designed to collect information. The questionnaire was administered through a physician as the authors expected low education levels among the FSWs. The participants were ensured confidentiality.

The questionnaire consisted of questions on demographic characteristics, sexual activities, use of contraceptive methods, assessing knowledge, and awareness about HPV infection risks. The number of sexual contacts per year was calculated by multiplying self-reported working days in the last year by the number of self-reported clients per day, and classified in two groups as expression of median.

Twelve questions were designed to assess knowledge and to be answered "yes/no" or "no idea". Each correct answer was scored as 1 , overall knowledge scores were classified to be very poor $(0-3)$, poor $(>3-6)$, moderate $(>6-9)$ and high $(>9-12)$.

Four questions were asked to collect information about awareness. The participants were requested to categorize themselves as "high", "moderate", "low", and "dont know" groups regarding risks of HPV infection, cervical cancer and of abnormal results of pap smear. They were scored from 1 to $4(0-1=$ very poor, $>1-2=$ poor,$>2-3=$ moderate, $>3-4=$ high $)$ and the same method applied for the knowledge score. The results were expressed as mean \pm standard deviation (SD).

\section{Statistical Analysis}

Statistical analysis was made using SPSS 15.0 software (Chicago, IL,USA). Evaluation of independent variables was determined by logistic regression analysis. The comparison of variables was analyzed by Pearson's $\chi^{2}$ test. P-value of $<0.05$ was considered statistically significant.

\section{RESULTS}

The demographic and sexual characteristics of brothel-based FSWs included in the study are given in Table 1.

A total of $152 \mathrm{FSWs}(63.6 \%)$ were over 30 years of age. Out of 239 women, $210(87.9 \%)$ had completed primary education. The median number of sexual contacts per year was 768 (range,
576-1,440). More than half of FSWs $(59.0 \%)$ had not used any barrier method. Approximately $62.0 \%$ smoked. As a barrier method, 122 (51\%) reported use of condom.

The rate of correct answers concerning the knowledge was generally lower than $20.0 \%$, as shown in Table 2 . Almost $70.0 \%$ of the participants knew that condom is a barrier method, and smoking increases cervical cancer risk. A total of 159 (66.5\%) FSWs had heard about sexually transmitted diseases in general, but considerably less (23.0\%) heard of HPV infection.

The knowledge score about HPV infection, the consequences of HPV infection, prevention, and pap smear screening were poor (3.66 \pm 1.34 ), and $75.7 \%$ of all FSWs had score of $\leq 4$. The score did not differ significantly with regards to the education level of participants $(p=0.318)$. Logistic regression analysis revealed no significant predictability of low education regarding the knowledge of HPV infection risks, i.e. there were no statistically significant differences between women who had less than primary education versus those who had higher education $(p=0.99)$. The knowledge scores were not significantly different between FSWs aged $\leq 30$ and more than 30 years of age $(p=0.427)$.

The ratio of answers to the questions that measure the awareness of participants about the risks of HPV infection, cervical cancer, and of abnormal pap smear results are shown in Table 3 . The awareness score was very low, for a mean of $0.60 \pm 0.68$, and did not differ significantly between educational groups $(p=0.238)$. Logistic regression analysis did not reveal low education level to be significant predictor of a very poor awareness $(p=0.863)$. Although overall awareness score was low for all FSWs, the difference was statistically significant between age groups $(\mathrm{p}=0.018)$.

Table 4 summarises frequencies of the scores, and statistical data of questionnaire according to age and education.

Table 1. Demographic and sexual characteristics of FSWs

\begin{tabular}{|l|c|}
\hline Parameters & Number (\% of total FSWs) \\
\hline Age (years) & $87(36.4)$ \\
\hline$\leq 30$ & $152(63.6)$ \\
\hline$>30$ & $210(87.9)$ \\
\hline Education level & $29(12.1)$ \\
\hline Primary school \\
\hline Secondary and/or high \\
\hline Smoking & $148(61.9)$ \\
\hline Yes & $91(38.1)$ \\
\hline No & \\
\hline Contraception methods & $122(51.0)$ \\
\hline Condom use & $39(16.3)$ \\
\hline Oral contraceptive use & $27(11.3)$ \\
\hline Intra uterine device (IUD) use & $142(59.4)$ \\
\hline No contraception & $166(69.5)$ \\
\hline Total number of sexual contacts per year (median) \\
\hline$\leq 768$ & $73(30.5)$ \\
\hline$>768$ &
\end{tabular}


Table 2. Knowledge about HPV infection

\begin{tabular}{|l|c|c|}
\hline Questions (correct answers) & $\begin{array}{c}\text { Number of correct answers } \\
\text { (\% of total) }\end{array}$ & $\begin{array}{c}\text { Number of false or no idea } \\
\text { (\% of total) }\end{array}$ \\
\hline Have you heard about HPV? (Yes) & $55(23.0)$ & $184(77.0)$ \\
\hline Are hepatitis, syphilis, and AIDS sexually transmitted diseases? (Yes) & $159(66.5)$ & $80(33.5)$ \\
\hline Is HPV a virus that may cause genital warts and cervical cancer? (Yes) & $21(8.8)$ & $218(91.2)$ \\
\hline Can HPV infection be prevented? (Yes) & $30(12.6)$ & $209(87.4)$ \\
\hline Does the risk of HPV infection increase with multiple factors? (Yes) & $37(15.5)$ & $202(84.5)$ \\
\hline Does smoking increase the risk of cervical cancer? (Yes) & $167(69.9)$ & $72(30.1)$ \\
\hline Is condom a barrier method? (Yes) & $169(70.7)$ & $70(29.3)$ \\
\hline Is cervical cancer the most common preventable cancer in women? (Yes) & $40(16.7)$ & $199(83.3)$ \\
\hline Is vaginal discharge a common sign of cervical cancer? (No) & $47(19.7)$ & $192(80.3)$ \\
\hline Should pap smear be done in the absence of any complaint? (Yes) & $83(34.7)$ & $156(65.3)$ \\
\hline Does abnormal pap smear indicate cervical cancer? (No) & $44(18.4)$ & $195(81.6)$ \\
\hline Is a vaccine present for prevention of HPV? (Yes) & $46(19.2)$ & $193(80.8)$ \\
\hline
\end{tabular}

Table 3. Awareness about HPV infection and cervical cancer

\begin{tabular}{|l|c|c|c|c|}
\hline Questions (correct answers) & No. of "high" (\%) & No. of "moderate" (\%) & No. of "low" (\%) & No. of "do not know" (\%) \\
\hline What is your risk of HPV infection? (High) & $31(13.0)$ & $24(10.0)$ & $26(10.9)$ & $158(66.1)$ \\
\hline What is your risk of cervical cancer? (High) & $50(20.9)$ & $35(14.6)$ & $36(15.1)$ & $118(49.4)$ \\
\hline $\begin{array}{l}\text { What is your risk of abnormal pap smear result? } \\
\text { (High) }\end{array}$ & $31(13.0)$ & $21(8.8)$ & $35(14.6)$ & $152(63.6)$ \\
\hline $\begin{array}{l}\text { What is the causative risk between HPV and } \\
\text { cervical cancer? (High) }\end{array}$ & $31(13.0)$ & $19(7.9)$ & $17(7.1)$ & $172(72.0)$ \\
\hline
\end{tabular}

Table 4. Frequencies and statistics of scores according to age and education levels

\begin{tabular}{|c|c|c|c|c|c|c|}
\hline & \multicolumn{2}{|c|}{ Freq. of the awareness scores } & \multirow{3}{*}{ p-value } & \multicolumn{2}{|c|}{ Freq. of the knowledge scores } & \multirow{3}{*}{$\mathrm{p}$-value } \\
\hline & $0-6$ & $>6$ & & $0-2$ & $>2$ & \\
\hline & no. $(\%)$ & no. $(\%)$ & & no. $(\%)$ & no. $(\%)$ & \\
\hline \multicolumn{7}{|l|}{ Education } \\
\hline Primary school & $203(96.6 \%)$ & $7(2.9 \%)$ & \multirow{2}{*}{0.318} & $186(77.8 \%)$ & $24(10.0 \%)$ & \multirow{2}{*}{0.863} \\
\hline Over & $29(12.1 \%)$ & $0(0.0 \%)$ & & $26(10.8 \%)$ & $3(1.2 \%)$ & \\
\hline \multicolumn{7}{|l|}{ Age } \\
\hline$\leq 30$ years age & $86(35.9 \%)$ & $1(0.4 \%)$ & \multirow{2}{*}{0.427} & $83(34.7 \%)$ & $4(1.6 \%)$ & \multirow{2}{*}{0.018} \\
\hline$>30$ years age & $146(61.0 \%)$ & $6(2.5 \%)$ & & $129(53.9 \%)$ & $23(9.6 \%)$ & \\
\hline
\end{tabular}

\section{DISCUSSION}

The results presented in this study provide a first insight into FSWs' knowledge and awareness about HPV infection and its consequences in Turkey. No data about this issue has been published in our country so far, and this kind of study has also been rarely published. By the way of increasing FSWs' knowledge about HPV infection and its consequences, the incidence rate of cervical cancer could be reduced in the future.

HPV infection is one of the most common sexually transmitted infections and high-risk types of HPV are a necessary cause of cervical cancer $(1,4,15,18)$. Approximately 500,000 women develop cervical cancer each year worldwide (3). Over $80 \%$ of cervical cancer cases and deaths can be prevented by effective, organized screening programmes (4). The prevalence of HPV infection among women in the general population in Turkey varies according to geographical region, from $2 \%$ to $20 \%(5,6)$. It is a major issue in our population as the incidence of cervical cancer reported by the Ministry of Health increased from $0.7 / 100,000$ in 1996 to $3.9 / 100,000$ in 2007 (16).

FSWs represent a group at the highest risk for HPV infection, and the increased risk has been attributed to a high number of 
sexual contacts, unsafe sex behaviour, smoking, and low socioeconomic status $(10,13,19)$. In our country, the prevalence of HPV infection among FSWs in the region, where the prevalence in women in the general population is relatively low $(2 \%)$, has been found to be $20 \%$ (unpublished data). The study conducted among women of the general population in Turkey revealed that the rate of knowledge about HPV infection and awareness about the existence of HPV vaccine was $24 \%$ (16). In this study we found that majority of participants were not aware of the risk of HPV infection and its consequencies. Although about $70 \%$ of FSWs correctly answered the question about the relation between smoking and cancer, this was not beyond the level of general public information. In our study, the rate of participants with primary school education level was quite high ( $88 \%$ of all FSWs) and the rate of those who never heard of HPV was also remarkable (77\%). In the study from Thailand, the rate of low educated participants was similarly high (55\%), and low education was an independent predictor of very low knowledge scores (7). On the other hand, in the study reported from Peruvian FSWs, the rate of participants that completed secondary and superior education was $94 \%$ of which $96 \%$ had heard of HPV (13). It was surprising that our analysis indicated that there was no association between the knowledge scores and the education level. This anomaly may be related to the lack of education on sexual health and related issues at school in our country, and to the lack of information provided through the different types of electronic media, particularly on TV. It is also noteworthy that special education techniques are required to transfer essential information to FSWs with low literacy skills.

A high level of disease awareness is a key indicator of the success of any programme $(20,21)$. Consequently, low level of awareness can impede any preventive measures to be taken, such as screening and vaccination. Therefore, effective interventions like launching targeted national informative campaigns and updating the knowledge of both primary healthcare workers and target populations on HPV infection and its consequences will promote awareness.

In conclusion, we suggest that FSWs' knowledge and awareness about HPV infection in Turkey require urgent intervention. It is important that women and men understand the implications of HPV infection. Strategies for reduction of HPV infection rate in targeted populations need to be developed. All sexually active women should be encouraged to have regular cervical cytology. Health professionals, schools and the media should collectively distribute information about the prevention of HPV infection and cervical cancer. Efforts should be made to design HPV-targeted educational programmes for all levels of the community.

\section{Conflict of interests}

None declared

\section{REFERENCES}

1. Muñoz N, Bosch FX, de Sanjosé S, Herrero R, Castellsagué X, Shah $\mathrm{KV}$, et al.; International Agency for Research on Cancer Multicenter Cervical Cancer Study Group. Epidemiologic classification of human papillomavirus types associated with cervical cancer. N Engl J Med. 2003 Feb 6;348(6):518-27.

2. Vonka V, Hamšíková E. Vaccines against human papillomaviruses - a major breakthrough in cancer prevention. Cent Eur J Public Health. 2007 Dec;15(4):131-9.
3. Ferlay J, Shin HR, Bray F, Forman D, Mathers C, Parkin DM. Estimates of worldwide burden of cancer in 2008: GLOBOCAN 2008. Int J Cancer. 2010 Dec 15;127(12):2893-917.

4. Grce M, Davies P, Arbyn M, Anttila A, Grubisić G, Kardum-Skelin I, et al. Report on the 2007 International Workshop on Human Papillomaviruses and Consensus Recommendations for Cervical Cancer Prevention. Cent Eur J Public Health. 2008 Mar;16(1):38-40.

5. Naki MM, Celik H, Api O, Toprak S, Ozerden E, Unal O. Awareness, knowledge and attitudes towards HPV infection and vaccine among non-obstetrician-gynecologist healthcare providers. J Turkish German Gynecol Assoc 2010;11(1):16-21.

6. Altun Z, Yarkin F, Vardar MA, Uguz AH. The Prevalence of human papilloma virus infection among women who admitted to Cukurova University Faculty of Medicine Hospital. Turkiye Klinikleri J Med Sci 2011;31(2):307-14. (In Turkish.)

7. Kietpeerakool C, Phianmongkhol Y, Jitvatcharanun K, Siriratwatakul U, Srisomboon J. Knowledge, awareness, and attitudes of female sex workers toward HPV infection, cervical cancer, and cervical smears in Thailand. Int J Gynaecol Obstet. 2009 Dec;107(3):216-9.

8. Shikova E, Todorova I, Ganchev G, Kouseva-Dragneva V, KalaschevaZaimova P. Prevalence of human papillomavirus infection among female sex workers in Bulgaria. Int J STD AIDS. 2011 May;22(5):278-80.

9. Yasar KK, Pehlivanoglu F, Sengoz G, Bakar M. Human papillomavirus frequency and typing in licensed sex workers. Zeynep Kamil Tip Bulteni 2010;41(4):177-81. (In Turkish.)

10. del Amo J, González C, Belda J, Fernández E, Martínez R, Gómez I, et al. Prevalence and risk factors of high-risk human papillomavirus in female sex workers in Spain: differences by geographical origin. J Womens Health (Larchmt). 2009 Dec;18(12):2057-64.

11. U. S. Food and Drug Administration. Vaccines, blood \& biologics. June 8, 2006 approval letter - human papillomavirus quadrivalent (types 6, 11, 16, 18) vaccine, recombinant [Internet]. Silver Spring: U. S. Food and Drug Administration [updated 2009 Apr 30; cited 2012 Feb 02]. Available from: http://www.fda.gov/BiologicsBloodVaccines/Vaccines/ ApprovedProducts/ucm 111283.htm.

12. Marek E, Dergez T, Rebek-Nagy G, Kricskovics A, Kovacs K, Bozsa S, et al. Adolescents' awareness of HPV infections and attitudes towards HPV vaccination 3 years following the introduction of the HPV vaccine in Hungary. Vaccine. 2011 Nov 3;29(47):8591-8.

13. Brown B, Carcamo C, Blas MM, Valderrama M, Halsey N. Peruvian FSWs: understanding HPV and barriers to vaccination. Vaccine. 2010 Nov 16;28(49):7743-7

14. Leddy MA, Anderson BL, Gall S, Schulkin J. Obstetrician-gynecologists and the HPV vaccine: practice patterns, beliefs, and knowledge. J Pediatr Adolesc Gynecol. 2009 Aug;22(4):239-46.

15. Klug SJ, Hukelmann M, Blettner M. Knowledge about infection with human papillomavirus: a systematic review. Prev Med. 2008 Feb;46(2):8798.

16. Onan A, Ozkan S, Korucuoglu U, Aksakal N, Taskiran C, Aygun R, et al. Knowledge on and attitude toward human papillomavirus infection and its vaccine in a Turkish subpopulation. Turkiye Klinikleri J Med Sci 2009;29(3):594-8.

17. Wright TC, Bosch FX, Franco EL, Cuzick J, Schiller JT, Garnett GP, et al. Chapter 30: HPV vaccines and screening in the prevention of cervical cancer; conclusions from a 2006 workshop of international experts. Vaccine. 2006;24 Suppl 3:S3/251-61.

18. de Villiers EM, Fauquet C, Broker TR, Bernard HU, zur Hausen H. Classification of papillomaviruses. Virology. 2004 Jun 20;324(1):17-27.

19. Tideman RL, Thompson C, Rose B, Gilmour S, Marks C, van Beek I, et al. Cervical human papillomavirus infections in commercial sex workersrisk factors and behaviours. Int J STD AIDS. 2003 Dec;14(12):840-7.

20. Crosby R, Rager K, Hanson A, Ribes J. Does knowing about an HPV infection influence behavior change? A feasibility study of females attending a teen clinic. J Pediatr Adolesc Gynecol. 2008 Dec;21(6):373-6.

21. Marks G, Crepaz N, Senterfitt JW, Janssen RS. Meta-analysis of high-risk sexual behavior in persons aware and unaware they are infected with HIV in the United States: implications for HIV prevention programs. J Acquir Immune Defic Syndr. 2005 Aug 1;39(4):446-53.

Received November 1, 2011 Accepted in revised form May 16, 2012 